\title{
Extranodal Rosai-Dorfman disease: a rare soft tissue neoplasm masquerading as a sarcoma
}

\author{
Mahathi Komaragiri ${ }^{1}$, Lauren S Sparber ${ }^{2}$, Maria Laureana Santos-Zabala ${ }^{3}$, Michael Dardik ${ }^{3}$ \\ and Ronald S Chamberlain ${ }^{1,2,4^{*}}$
}

\begin{abstract}
Introduction: Rosai-Dorfman disease (RDD) is a rare proliferative histiocytic disorder of unknown etiology. RDD typically presents with generalized lymphadenopathy and polymorphic histiocytic infiltration of the lymph node sinuses; however, occurrences of extranodal soft tissue RDD may rarely occur when masquerading as a soft tissue sarcoma.

Materials and methods: A comprehensive search of all published cases of soft tissue RDD without associated lymphadenopathy was conducted using PubMed and Google Scholar for the years 1988 to 2011. Ophthalmic RDD was excluded.

Results: Thirty-six cases of extranodal soft tissue RDD, including the current one, have been reported since 1988. Anatomical distribution varied among patients. Four (11.1\%) patients presented with bilateral lesions in the same anatomic region. Pain was the most common symptom in six (16.8\%) patients. Sixteen (41.6\%) patients were managed surgically, of which one (2.8\%) case experienced recurrence of disease.

Conclusion: RDD is a rare inflammatory non-neoplastic process that should be considered in the differential diagnosis of a soft tissue tumor. Thus, differentiation of extranodal RDD from more common soft tissue tumors such as soft tissue sarcoma or inflammatory myofibroblastic tumor is often difficult and typically requires definitive surgical excision with histopathological examination. While the optimal treatment for extranodal RDD remains ill-defined and controversial, surgical excision is typically curative.
\end{abstract}

Keywords: Rosai-Dorfman disease soft tissue, Rosai-Dorfman disease cutaneous, Sinus histiocytosis with massive lymphadenopathy

\section{Background}

Sinus histiocytosis with massive lymphadenopathy (SHML) is a class II histiocytosis first described as a unique clinicopathologic entity by Rosai and Dorfman in 1969 [1]. Although lymph nodes are more commonly involved, any organ may be affected - thus the term RDD has been adopted in place of SHML [1]. A rare disease, RDD is distributed worldwide, predominantly affecting young people and with a slight male predominance [2]. The disease typically presents with bilateral painless lymphadenopathy of the head and neck as well as fever, leukocytosis, elevated erythrocyte sedimentation rate and polyclonal hypergammaglobulinemia [3,4]. Extranodal

\footnotetext{
* Correspondence: rchamberlain@barnabashealth.org

${ }^{2}$ Department of Surgery, Saint Barnabas Medical Center, 94 Old Short Hills Road, Livingston, NJ 07039, USA

Full list of author information is available at the end of the article
}

presentations have also been described, with the most common sites including skin and nasal sinuses [4]. RDD is considered a non-neoplastic manifestation with a selflimited course; however, it may also undergo exacerbations and remissions rendering treatment to be necessary [2]. Histologically, RDD classically shows an inflammatory infiltrate rich in lymphocytes, plasma cells and large histiocytes [4]. RDD histiocytes are unique because they phagocytose intact lymphocytes and other immune cells, a histological hallmark of the disease termed emperipolesis [5]. The largest report of RDD (1969) involved 423 cases, with 182 patients having extranodal disease [3]. Only 13 patients in this series presented with soft-tissue RDD without detectable lymphadenopathy [3]. Here we describe an unusual case of RDD in a middle-aged African American female presenting as a painful right medial thigh mass.

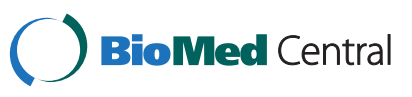




\section{Case presentation}

A 56-year-old African American female presented to the Saint Barnabas Medical Center (Livingston, NJ, USA) with a 1-year history of an enlarging painful right medial thigh mass. Her medical history was significant for hypertension, diabetes, hypercholesterolemia, degenerative disk disease and asthma. The mass was noted to be extremely painful and was located anterior and superficial to the adductor muscle group in the right medial thigh. The patient reported a pulling, painful sensation in the knee joint as well as discomfort upon standing for long periods of time. She denied any constitutional symptoms and had no reported neurological deficits. No weight loss was reported. A chest, abdomen, and pelvis computed tomography scan was performed, demonstrating no systemic adenopathy. A magnetic resonance imaging study of the right lower extremity was obtained and revealed a $7 \mathrm{~cm} \times$ $5 \mathrm{~cm} \times 3.2 \mathrm{~cm}$ ill-defined, enhancing soft tissue mass, suspicious for a soft tissue sarcoma located in the deep subcutaneous tissues of the right thigh, adjacent to the vastus medialis muscle (Figure 1). The lesion was suspicious for a primary malignancy/sarcoma and the patient underwent a core biopsy of the lesion. Biopsy results showed an inflammatory mass most consistent with an inflammatory myofibroblastic tumor. However, the tissue sample was limited and a diagnosis of sarcoma could not be excluded. An incisional biopsy was then completed that demonstrated an inflammatory pseudotumor with mesenchymal

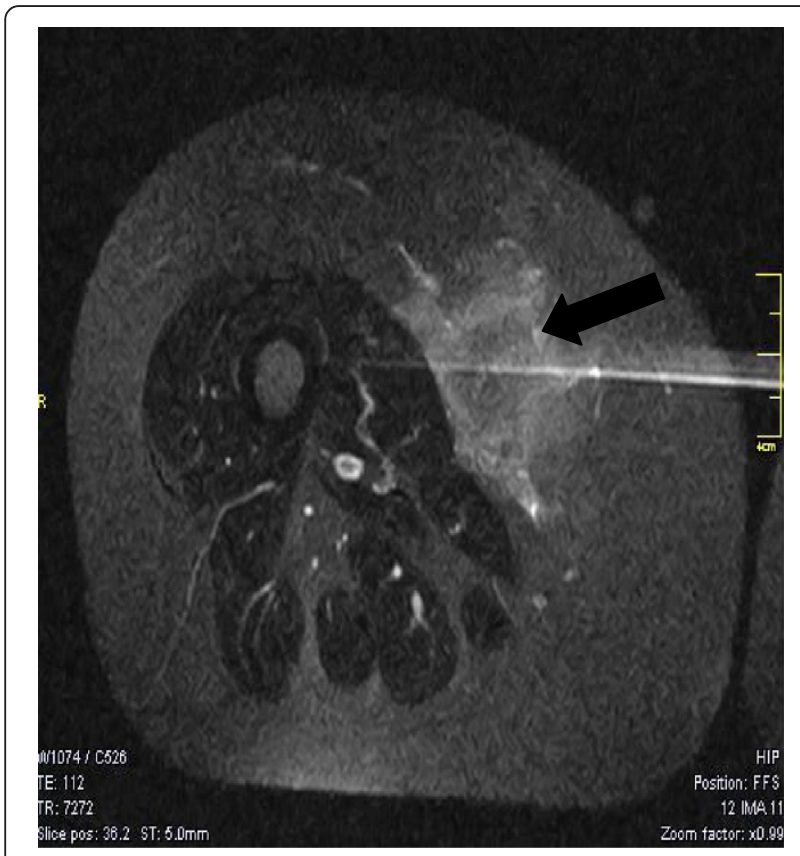

Figure 1 Large radiolucent mass in the right medial thigh. T1weighted transverse magnetic resonance image of the right lower extremity demonstrating a large radiolucent mass in the right medial thigh (black arrow). fatty and fibroblastic proliferation and prominent inflammatory cell infiltration. There was no evidence of any atypia or identifiable lymphoma. The mass was positive for Vimentin and BCL-2, and was negative for all other markers including desmin, smooth muscle actin, CD34, AE1, S-100, p53 ALK-1 and EBER-RNA. The patient's symptoms progressed and a wide local excision of the mass was completed.

On gross examination, the specimen weighed $357 \mathrm{~g}$. There was an ill-defined, firm, yellow to tan mass deep within the subcutaneous tissue that measured $8 \mathrm{~cm} \times$ $7.5 \mathrm{~cm} \times 6 \mathrm{~cm}$. The mass had a fleshy cut surface. There were no overlying skin changes. Microscopic examination demonstrated a mixed inflammatory background including lymphocytes, plasma cells, polymorphonuclear leukocytes and small areas of bland fibroblasts (Figure 2a,b). There were large aggregates of pale-staining histiocytes demonstrating emperipolesis (Figure 2c). Immunohistochemical stains for S-100 and CD68 were strongly positive (Figure 3a,b) in the histiocytes. Fluorescence in situ hybridization was negative for MDM2 gene amplification, excluding a well-differentiated liposarcoma. The above immunophenotype and characteristic histological findings of emperipolesis were consistent with a final pathologic diagnosis of extranodal RDD.

Postoperatively the patient had experienced persistent but resolving right medial thigh pain and was referred for physiotherapy. At the patient's 9-month follow-up, there was no recurrence of the tumor on the right side and the painful symptoms were resolving. However, she then presented with a relatively nontender $2 \mathrm{~cm} \times 4 \mathrm{~cm}$ cystlike mass on the left medial thigh in the popliteal region. Magnetic resonance imaging demonstrated a $5.3 \mathrm{~cm} \times 4$ $\mathrm{cm} \times 1.6 \mathrm{~cm}$ area consistent with either a lymphangioma or resolving necrosis from a residual mass. Core biopsy results yielded extranodal RDD with cells positive for S-100, CD68 and CD117. The sample was negative for AE1/3 and CD34. CD1a testing was not performed on the core biopsy. An excisional biopsy was performed and on gross examination the specimen was a fragment of tan-yellow adipose tissue measuring $7 \mathrm{~cm} \times 6 \mathrm{~cm} \times 1.5 \mathrm{~cm}$, with a poorly defined tan-colored region of induration measuring $2 \mathrm{~cm} \times 1.2 \mathrm{~cm} \times 1 \mathrm{~cm}$. Microscopic examination was once again consistent with extranodal RDD confirmed with immunohistochemical stains (positive for S-100 and CD68). CD1a immunohistochemical staining was not performed on the excisional biopsy tissue.

\section{Results}

A comprehensive search of all published cases of soft tissue RDD without associated lymphadenopathy was conducted using PubMed and Google Scholar for the years 1988 to 2011. Ophthalmic RDD was excluded. Among reported cases of Rosai-Dorfman tumors, 43\% of 

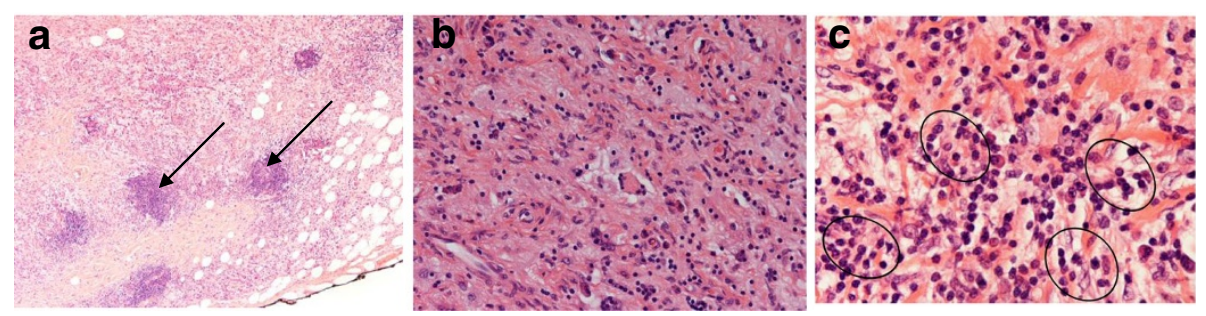

Figure 2 Microscopic examination of right medial thigh mass demonstrating characteristic emperipolesis. (a) Groups of lymphoid aggregates (black arrow) and scattered pale areas of fibroadipose tissue ( $\mathrm{H} \& \mathrm{E}$ stain, original magnification $\times 10)$. (b) Histiocytes and multinucleated cells among mixed inflammatory cells that include plasma cells and lymphocytes (H \& E stain, original magnification $\times 20)$. (c) Histiocytes engulfing lymphocytes and plasma cells (emperipolesis) ( $\mathrm{H} \& \mathrm{E}$ stain, original magnification $\times 40$ ).

patients had extranodal disease with associated lymphadenopathy; however, only $3 \%$ of the patients had soft tissue RDD without detectable lymph node involvement $[3,5,6]$. Overall, 36 cases of extranodal soft tissue RDD had been documented since 1969, including the current case. Clinical and treatment data for all reported soft tissue RDD are detailed in Table 1 . Among these 36 patients, $17(47.2 \%)$ patients were male and 19 (52.7\%) patients were female (male:female ratio, 0.89:1). The overall mean age was 45.3 years (range 10 months to 72 years), with a mean age for males and females of 45.8 and 47.0 years, respectively. The most common anatomic location for extranodal soft tissue RDD was the lower extremity (38.9\%), followed by the upper extremity (36.1\%), the torso (36.1\%) and the head and neck (19.4\%). Many patients $(41.6 \%)$ presented with multiple lesion sites, with much fewer $(11.1 \%)$ presenting with bilateral lesions in the same anatomic region. Pain was the most commonly reported symptom (16.8\%). Surgical resection was described in 16 cases $(41.6 \%)$, of which only one case $(2.8 \%)$ experienced recurrence of disease. The remaining 19 cases $(52.8 \%)$ were managed medically with dapsone, steroids or observation. Of these patients, some patients (11.1\%) experienced spontaneous resolution, other cases (13.9\%) had partial regression, while no changes were observed in seven (19.4\%) cases and one patient $(2.8 \%)$ experienced regrowth of the tumor. Of the reported cases, three patients $(8.3 \%)$ had no reported follow-up while one case $(2.8 \%)$ did not report treatment. Among cases in which immunohistochemistry was performed, 34 cases $(94.4 \%)$ were reactive to $\mathrm{S}-100$ stain and 30 cases (83.3\%) were reactive to CD68 stain.

\section{Discussion}

A class II histiocytosis, RDD was first described as a distinct clinicopathologic entity by Rosai and Dorfman in 1969 [1]. A rare disease, RDD is distributed worldwide with $80 \%$ of cases occurring in children and young adults [16]. RDD exhibits a slight male predominance (58\%) and a general predilection for individuals of African descent [16]. The largest study of RDD was conducted by Foucar, Rosai and Dorfman in 1990 and included 423 cases with a histopathological diagnosis of RDD [3].

RDD is of unknown etiology, although viral agents such as human herpes virus-6 and Epstein-Barr virus are thought to play a role in the pathogenesis via immune system dysregulation $[17,18]$. Levine and colleagues detected human herpes virus-6 via in situ hybridization in seven of nine SHML cases, while Luppi and colleagues had demonstrated human herpes virus- 6 antigen expression by abnormal histiocytes $[19,20]$. Both sets of data suggested a causative role for human herpes virus- 6 virus.
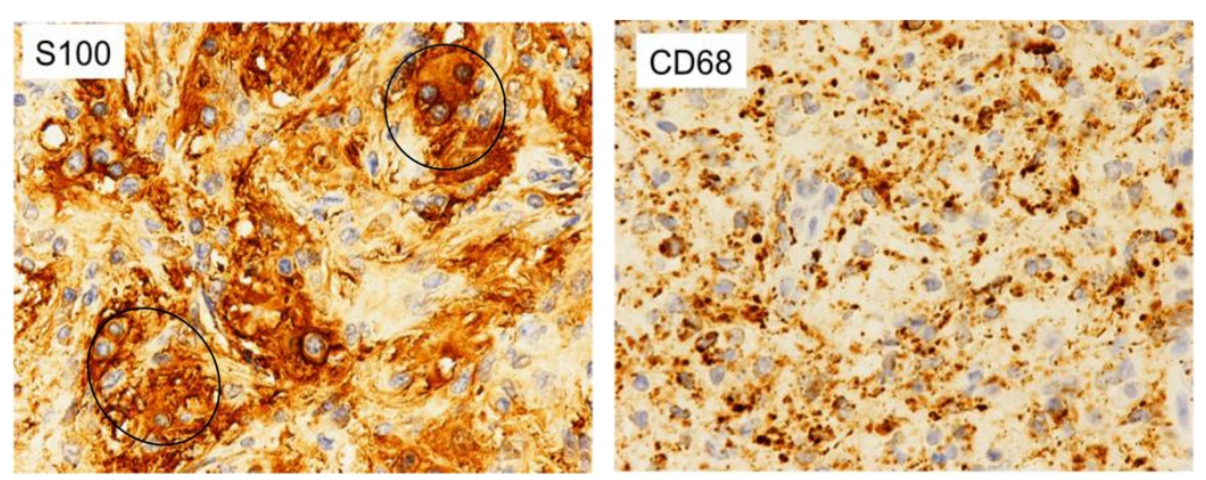

Figure 3 Immunohistochemical staining of the right medial thigh mass. Immunohistochemical stains are positive for (a) S-100 and (b) CD68 (original magnification $\times 20$ ). 
Table 1 Results of all published reports of extranodal soft tissue Rosai Dorfman disease (1988 to 2012)

\begin{tabular}{|c|c|c|c|c|c|c|c|c|}
\hline Case & Study & Location & $\begin{array}{l}\text { Age } \\
\text { (years) }\end{array}$ & Sex & Presenting symptoms & IHC & $\begin{array}{l}\text { Surgical } \\
\text { excision }\end{array}$ & Status after diagnosis and treatment \\
\hline 1 & $\begin{array}{l}\text { Suster et al, } \\
1988[7]\end{array}$ & $\begin{array}{l}\text { Lateral upper right arm and } \\
\text { middle third of left thigh }\end{array}$ & 72 & $\mathrm{~F}$ & Multiple firm flesh-colored subcutaneous nodules & S-100+ & No & 7 years; spontaneous resolution \\
\hline 2 & $\begin{array}{l}\text { Rasool et al, } \\
1996[8]\end{array}$ & Right index finger & $10 \mathrm{mo}$ & $\mathrm{F}$ & $\begin{array}{l}\text { Right index finger swelling, pain, axilla, axillary lymph } \\
\text { node }\end{array}$ & NR & Yes & 14 months, no recurrence \\
\hline \multirow[t]{2}{*}{3} & \multirow{2}{*}{$\begin{array}{l}\text { Govender et al, } \\
1997[9]\end{array}$} & \multirow[t]{2}{*}{ Chest wall } & \multirow[t]{2}{*}{34} & \multirow[t]{2}{*}{$\mathrm{F}$} & \multirow[t]{2}{*}{ Superficial firm mass } & S-100+ & \multirow[t]{2}{*}{ Yes } & \multirow[t]{2}{*}{6 months, no recurrence } \\
\hline & & & & & & CD68+ & & \\
\hline \multirow[t]{2}{*}{4} & \multirow{2}{*}{$\begin{array}{l}\text { Child et al, } 1998 \\
\text { [10] }\end{array}$} & \multirow[t]{2}{*}{ Posterior left thigh } & \multirow[t]{2}{*}{36} & \multirow[t]{2}{*}{$\mathrm{F}$} & \multirow{2}{*}{$\begin{array}{l}\text { Hyperpigmented indurated plaque with multiple } \\
\text { nodules, occasional pain }\end{array}$} & S-100+ & \multirow[t]{2}{*}{ No } & \multirow{2}{*}{$\begin{array}{l}12 \text { months; no new lesions, new nodules } \\
\text { within plaque }\end{array}$} \\
\hline & & & & & & CD68+ & & \\
\hline \multirow[t]{2}{*}{5} & \multirow{2}{*}{$\begin{array}{l}\text { Quaglino et al, } \\
1998 \text { [11] }\end{array}$} & \multirow[t]{2}{*}{ Skin of arms and buttocks } & \multirow[t]{2}{*}{70} & \multirow[t]{2}{*}{$\mathrm{F}$} & \multirow[t]{2}{*}{ Nodules on arms, face, buttock } & S-100+ & \multirow[t]{2}{*}{ NR } & \multirow[t]{2}{*}{ NR } \\
\hline & & & & & & CD1a- & & \\
\hline \multirow[t]{2}{*}{6} & \multirow{2}{*}{$\begin{array}{l}\text { Huang et al, } \\
2001[12]\end{array}$} & \multirow[t]{2}{*}{ Medial right upper arm } & \multirow[t]{2}{*}{43} & \multirow[t]{2}{*}{$\mathrm{F}$} & Numbness and paresthesias of forearm and wrist & S-100+ & Yes & 12 months; no recurrence, mild hypoesthesia \\
\hline & & & & & & CD68+ & & \\
\hline 7 & Stefanato et al, & Upper back, thighs, feet & 55 & $\mathrm{~F}$ & Firm reddish brown dome-shaped papules with a single & S-100+ & No & 24 months; spontaneous resolution \\
\hline & & & & & episode of belpharoconjunctivitis & CD1a- & & \\
\hline 8 & $\begin{array}{l}\text { Yoon et al, } 2005 \\
{[5]}\end{array}$ & $\begin{array}{l}\text { Left ankle, right forearm and } \\
\text { arm }\end{array}$ & 36 & M & Nontender mobile nodules, left ankle pain, epistaxis & S-100+ & Yes & 4 months; recurrence in right maxillary sinus \\
\hline 9 & Kong et al, 2007 & Upper right arm & 55 & M & Flat-topped papules and nodules & S-100+ & No & 55 months; spontaneous resolution \\
\hline & & & & & & CD68+ & & \\
\hline 10 & Kong et al, 2007 & Left thigh and back & 65 & M & Brown plaque and nodules & S-100+ & No & 31 months; partial regression \\
\hline & & & & & & CD68+ & & \\
\hline 11 & Kong et al, 2007 & Left thigh & 49 & $\mathrm{~F}$ & Red to brown nodules, tenderness & S-100+ & No & 31 months; partial regression \\
\hline & & & & & & CD68+ & & \\
\hline 12 & Kong et al, 2007 & Left chest & 51 & M & Pinkish papules & S-100+ & Yes & 28 months; no recurrence at original site but \\
\hline & & & & & & CD68+ & & app \\
\hline 13 & Kong et al, 2007 & Left upper back & 52 & M & Red to dark-red papules, pruritis & S-100+ & No & 27 months; spontaneous resolution \\
\hline & & & & & & CD68+ & & \\
\hline 14 & Kong et al, 2007 & Lower back & 45 & M & Clusters of pinkish papules & S-100+ & Yes & 26 months; no recurrence \\
\hline & & & & & & CD68+ & & \\
\hline 15 & Kong et al, 2007 & Upper left arm & 52 & $\mathrm{~F}$ & Red to brownish plaque with scattered papules and & S-100+ & Yes & 8 months, no recurrence \\
\hline & & & & & & CD68+ & & \\
\hline & & & & & & CD1a+ & & \\
\hline 16 & Kong et al, 2007 & Right thigh and left calf & 55 & M & Hyperpigmented infiltrated plaque with papules & S-100+ & No & 24 months; persistence \\
\hline & & & & & & CD68+ & & \\
\hline
\end{tabular}


Table 1 Results of all published reports of extranodal soft tissue Rosai Dorfman disease (1988 to 2012) (Continued)

\begin{tabular}{|c|c|c|c|c|c|c|c|c|}
\hline 17 & $\begin{array}{l}\text { Kong et al, } 2007 \\
{[1]}\end{array}$ & Left arm and right thigh & 70 & $\mathrm{~F}$ & $\begin{array}{l}\text { Erythematous papuloplaques with papulovesicles and } \\
\text { pustules, pruritis }\end{array}$ & $\begin{array}{l}\text { S-100+ } \\
\text { CD68+ }\end{array}$ & No & 24 months; partial regression \\
\hline \multirow[t]{2}{*}{18} & \multirow{2}{*}{$\begin{array}{l}\text { Kong et al, } 2007 \\
{[1]}\end{array}$} & \multirow[t]{2}{*}{ Left arm and sacral back } & \multirow[t]{2}{*}{48} & \multirow[t]{2}{*}{ M } & \multirow[t]{2}{*}{ Pinkish to red papules } & S-100+ & \multirow[t]{2}{*}{ No } & \multirow[t]{2}{*}{ NR } \\
\hline & & & & & & CD68+ & & \\
\hline \multirow[t]{2}{*}{19} & \multirow{2}{*}{$\begin{array}{l}\text { Kong et al, } 2007 \\
\text { [1] }\end{array}$} & \multirow[t]{2}{*}{ Left thigh } & \multirow[t]{2}{*}{49} & \multirow[t]{2}{*}{$\mathrm{F}$} & \multirow[t]{2}{*}{ Brownish indurated plaque with satellite papules } & S-100+ & \multirow[t]{2}{*}{ No } & \multirow[t]{2}{*}{24 months; persistence } \\
\hline & & & & & & CD68+ & & \\
\hline \multirow[t]{2}{*}{20} & \multirow{2}{*}{$\begin{array}{l}\text { Kong et al, } 2007 \\
\text { [1] }\end{array}$} & \multirow[t]{2}{*}{ Left thigh and back } & \multirow[t]{2}{*}{43} & \multirow[t]{2}{*}{ M } & Confluent papules and erythematous plaque & S-100+ & Yes & 7 months; no recurrence \\
\hline & & & & & & CD68+ & & \\
\hline 21 & Kong et al, 2007 & Right thigh & 45 & M & Plane hyperpigmented plaque & S-100+ & Yes & 15 months; no recurrence \\
\hline & & & & & & CD68+ & & \\
\hline 22 & Kong et al, 2007 & Suprasternal fossa and sacral & 56 & $\mathrm{~F}$ & Two dome-shaped, exophytic masses surrounded by & S-100+ & Yes & 15 months; no recurrence \\
\hline & & & & & & CD68+ & & \\
\hline 23 & Kong et al, 2007 & Right upper back & 47 & M & Single dark-red nodule & S-100+ & Yes & 14 months; no recurrence \\
\hline & & & & & & CD68+ & & \\
\hline 24 & Kong et al, 2007 & Abdomen and right buttock & 21 & M & Confluent papules and infiltrated plaque dotted with & S-100+ & No & 12 months; slowly growing \\
\hline & & & & & & CD68+ & & \\
\hline 25 & Kong et al, 2007 & Upper right arm & 42 & M & Grouped pinkish papules, pain of wrist and shoulder & S-100+ & No & 11 months; persistence \\
\hline & & & & & & CD68+ & & \\
\hline 26 & Kong et al, 2007 & Face, buttock, abdomen and & 22 & $\mathrm{~F}$ & Multiple coalescing nodules, erythematous patches and & S-100+ & No & NR \\
\hline & & & & & plaques, some with tumorous appearance, pru & CD68+ & & \\
\hline 27 & Kong et al, 2007 & Cheek, back and buttock & 54 & M & Dark-red and brownish nodules & S-100+ & No & NR \\
\hline & & & & & & CD68+ & & \\
\hline 28 & Kong et al, 2007 & Upper left arm & 52 & $F$ & Single subcutaneous mass, fever & S-100+ & Yes & 9 months, no recurrence \\
\hline & & & & & & CD68+ & & \\
\hline 29 & Kong et al, 2007 & Right cheek & 40 & M & Erythematous papuloplaque & S-100+ & No & 6 months; partial regression \\
\hline & & & & & & CD68+ & & \\
\hline 30 & Kong et al, 2007 & Right cheek & 52 & $F$ & Erythematous papuloplaque & S-100+ & No & 5 months; persistence \\
\hline & & & & & & CD68+ & & \\
\hline 31 & Kong et al, 2007 & Left cheek and neck & 38 & M & Erythematous papuloplaque & S-100+ & No & 2 months; persistence \\
\hline & & & & & & CD68+ & & \\
\hline 32 & Penna Costa et & Left paravertebral mass in & 49 & $F$ & Dyspnea and cough and cervical lymphadenopathy & S-100+ & Yes & 12 months; no recurrence \\
\hline & 09 [3] & posterior mediastinum & & & & CD68+ & & \\
\hline & & & & & & CD1a- & & \\
\hline
\end{tabular}


Table 1 Results of all published reports of extranodal soft tissue Rosai Dorfman disease (1988 to 2012) (Continued)

\begin{tabular}{|c|c|c|c|c|c|c|c|c|}
\hline \multirow[t]{2}{*}{33} & \multirow{2}{*}{$\begin{array}{l}\text { Potts et al, } 2008 \\
\text { [2] }\end{array}$} & \multirow[t]{2}{*}{ Right forearm } & \multirow[t]{2}{*}{31} & \multirow[t]{2}{*}{$\mathrm{F}$} & \multirow[t]{2}{*}{ Firm, hyperpigmented mass } & \multirow[t]{2}{*}{ NR } & \multirow[t]{2}{*}{ Yes } & 8 months; recurrence \\
\hline & & & & & & & & 7 months after re-excision; no recurrence \\
\hline \multirow[t]{4}{*}{34} & \multirow{4}{*}{$\begin{array}{l}\text { Molina-Garrido } \\
\text { et al, } 2011[14]\end{array}$} & \multirow{4}{*}{$\begin{array}{l}\text { Parieto-occipital cutaneous } \\
\text { lesion }\end{array}$} & \multirow[t]{4}{*}{43} & \multirow[t]{4}{*}{ M } & \multirow[t]{4}{*}{ Red-yellow nodule, pain in right inferior maxillary area } & S-100+ & \multirow[t]{4}{*}{ Yes } & \multirow[t]{4}{*}{3 months; no recurrence } \\
\hline & & & & & & CD68+ & & \\
\hline & & & & & & CD1a- & & \\
\hline & & & & & & CD20- & & \\
\hline \multirow[t]{3}{*}{35} & \multirow{3}{*}{$\begin{array}{l}\text { Shi et al, } 2011 \\
{[15]}\end{array}$} & \multirow[t]{3}{*}{ Face, neck extremities } & \multirow[t]{3}{*}{45} & \multirow[t]{3}{*}{$\mathrm{F}$} & \multirow[t]{3}{*}{ Nonpruiginous papulonodular plaques } & S-100+ & \multirow[t]{3}{*}{ No } & \multirow[t]{3}{*}{5 weeks; partial regression } \\
\hline & & & & & & CD68+/- & & \\
\hline & & & & & & CD1a- & & \\
\hline \multirow[t]{2}{*}{36} & \multirow[t]{2}{*}{ Current study } & \multirow{2}{*}{$\begin{array}{l}\text { Medial right thigh; Medial left } \\
\text { thigh }\end{array}$} & \multirow[t]{2}{*}{56} & \multirow[t]{2}{*}{$\mathrm{F}$} & \multirow[t]{2}{*}{ Enlarging mass, knee joint pain } & S-100+ & \multirow[t]{2}{*}{ Yes } & \multirow{2}{*}{$\begin{array}{l}9 \text { months; no recurrence on right but new } \\
\text { lesion on left }\end{array}$} \\
\hline & & & & & & CD68+ & & \\
\hline
\end{tabular}

Totals: Mean age 46.3 years (10 months to 72 years); 17 male (M):19 female (F). Surgical excision: 16 yes, 19 not reported (NR).

IHC, immunohistochemistry; S-100, protein 100\% soluble in ammonium sulfate; CD68, cluster of differentiation 68; CD1a, cluster of differentiation 1a; CD20, cluster of differentiation 20. 
Levine and colleagues also detected Epstein-Barr virus DNA by in situ hybridization; however, this was detected in only one of nine SHML cases, suggesting that EpsteinBarr virus infection is probably not causative but may be a contributing factor to the development of RDD [9]. Yoon and colleagues had theorized that the initiation of monocyte colony-stimulating factor-mediated histoproliferation in RDD is an abnormal reaction of the hematolymphoid system to infection, leading to a high level of immune activation and subsequent cytosis [5]. However, the pathogenesis of RDD is still poorly understood but is likely multifactorial, with many of the documented patients having a variety of coexisting immunologically mediated disorders such as asthma, systemic lupus erythematosus, rheumatoid arthritis and hemolytic anemia $[2,21]$.

RDD is classified as either nodal or systemic (cutaneous, respiratory and/or osseous). RDD typically presents insidiously with generalized lymphadenopathy and a polymorphic histiocytic infiltration of the lymph node sinuses. The cervical lymph nodes are most commonly affected, followed by inguinal, axillary and mediastinal lymph node basins [18]. RDD may mimic a more malignant prognosis; however its clinical course varies from spontaneous regression to progressive lymphadenopathy and prolonged phases of stable disease [18,22]. Although a rare complication, death is usually a result of nodular

Table 2 Clinical features of Rosai-Dorfman disease and other common and uncommon soft tissue tumors

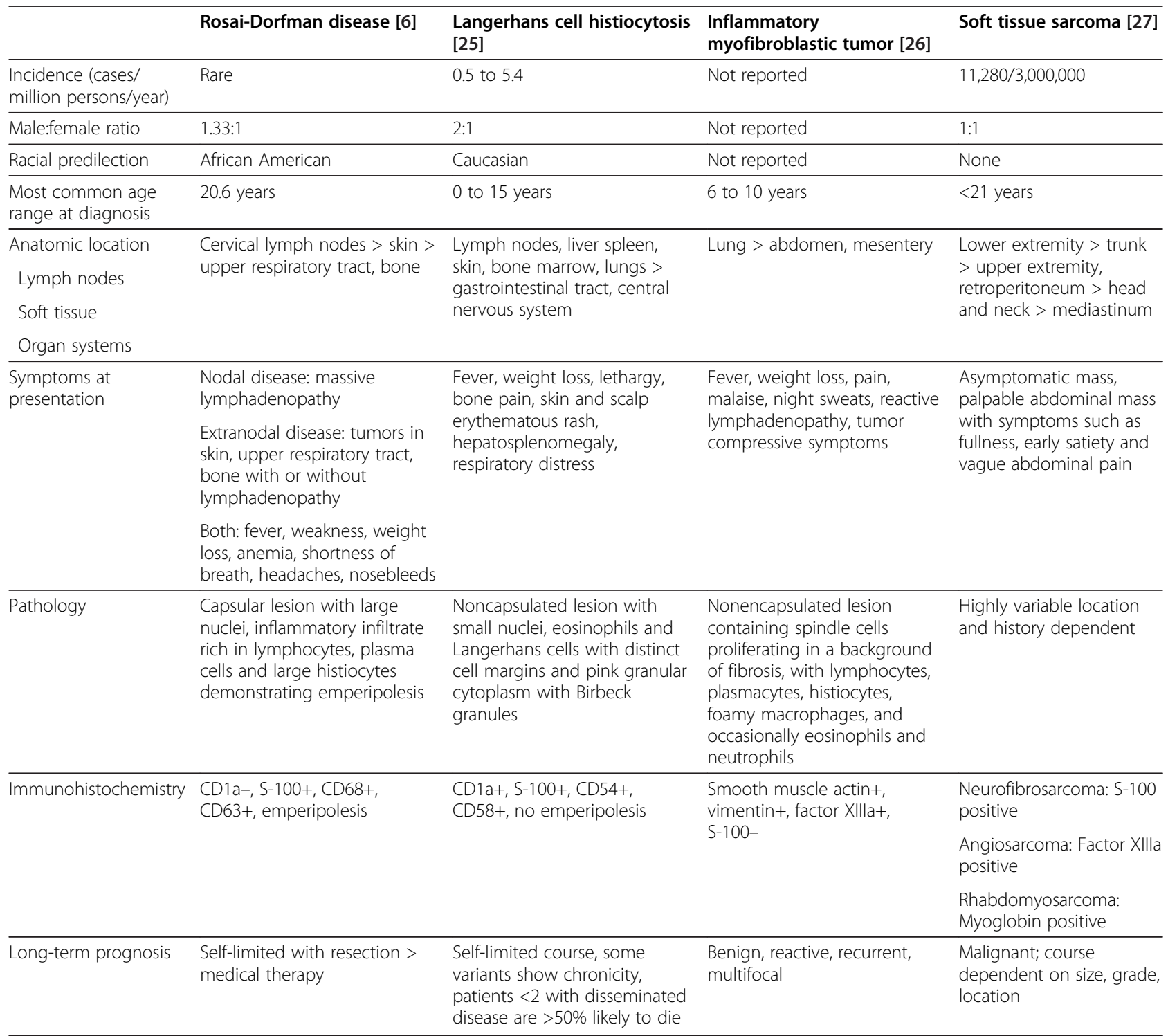


expansion into vital organs with interference of normal organ function. Complications leading to death are otherwise not well described among existing reports [18].

Systemic RDD is more prevalent and is characterized by tumors at other sites such as bone, upper respiratory tract, skin and retro-orbital tissue [23]. The cutaneous form involves only the skin and adjacent soft tissue without associated involvement of lymph nodes or other organs [2]. The cutaneous form occurs in one-third of cases, with skin and head and neck being the most commonly affected sites [17].

The differential diagnosis for RDD is challenging and is based on clinical features as well as immunohistological analysis and radiographic features. Lymph nodes tend to be hypermetabolic and positive on positron emission tomography. Upwards of $80 \%$ of patients demonstrate polyclonal hypergammaglobulinemia and as many as $65 \%$ have a hypochromic or normochromic normocytic anemia [16]. Histologically, RDD is characterized by an accumulation of proliferating histiocytes primarily in the sinusoids of lymph nodes [5]. RDD histiocytes phagocytose intact lymphocytes and other immune cells, leading to the disease's histological hallmark finding of emperipolesis [5]. Immunohistochemically, RDD is typically positive for S100 and CD68 antigens and negative for CD1a antigens [24]. However, it is important to note that CD1a reactivity is more typical of Langerhans cell histiocytosis (LCH) while S-100 reactivity is more characteristic of RDD [6]. While computed tomography and magnetic resonance imaging are not diagnostic of RDD, they can exclude other possible diagnoses as well as being useful to assess local disease extension [18].

The differential diagnoses of RDD-type lesions include lymphoreticular malignancies when cervical lymphadenopathy is present or soft tissue sarcomas when patients present with extranodal disease. Table 2 details a comparison of the demographics, presenting symptoms, and histological appearance of $\mathrm{RDD}, \mathrm{LCH}$, inflammatory myofibroblastic tumor and soft tissue sarcoma. A lack of cytologic atypia typically dispels more malignant diagnoses, and immunohistochemistry profiles will demonstrate a macrophage-induced histiocytosis with emperipolesis [28]. It is also important to clearly distinguish RDDsimilar S-100-positive histiocytoses such as malignant histiocytosis and LCH [1]. Malignant histiocytosis demonstrates marked cytologic atypia as well as high mitotic activity, while $\mathrm{LCH}$ tends to be CD1a positive with microscopic evidence of Birbeck granules [1]. In addition, neither malignant histiocytosis nor LCH demonstrate the hallmark finding of emperipolesis [1]. The more rare reticulohistiocytoma may be S-100-positive; however, this disease shows prominent ground glass appearance, abundant periodic acid Schiff-positive stain and fewer inflammatory cells in the background. These marker-specific differences are useful in providing a definitive diagnosis.

Soft tissue RDD is particularly challenging to diagnose since it is often difficult to discern the exact morphology of soft tissue samples. Extranodal soft tissue RDD usually demonstrates a spindled morphology with abundant collagen deposition resulting in the hallmark emperipolesis to become more inconspicuous [6]. Furthermore, the whorled pattern that is typically seen in soft tissue RDD can also mislead clinicians to diagnose either benign or malignant fibrohistiocytosis [6]. In general, however, cells of soft tissue fibrohistiocytic lesions, such as benign fibrous histiocytoma or dermatofibrosarcoma protuberans, usually have a higher nuclear to cytoplasmic ratio, more hyperchromatic nuclei and a more distinctive whorled pattern than those of soft tissue RDD [6].

Due to the rarity of the disease and its self-limited course, no treatment protocol has been established for RDD [18]. In symptomatic cases where the disease does not resolve spontaneously, surgical excision is typically performed. Symptomatic cases respond to steroids, alkylating agents and IFN $\alpha$, all with varying success rates [29]. The role of radiotherapy is still poorly understood, with some reports describing full resolution while others showed no response [18,22].

Although RDD in extremities had been described in a limited number of cases, this case highlighted the importance of better differentiation from more common malignancies. The painful symptoms experienced both before and after resection in the current case were uncharacteristic, as most patients with extranodal RDD had experienced pain-free results following resection. Furthermore, the development of bilateral disease in a different site had been only rarely reported $[1,5,14,16]$.

\section{Conclusions}

In summary, a defined treatment strategy for RDD has not been well described, given the rarity of the lesions and the difficulty in diagnosing them preoperatively. To date, surgical resection has proven most successful in preventing recurrences. Only one case of local recurrence for extranodal soft tissue RDD following surgical resection has been reported. However, as in the current case, bilateral disease presentation is also possible and requires close clinical follow-up. Given the rarity and indolence of RDD, surveillance cannot be endorsed; however, it is important to consider extranodal soft tissue RDD amongst the differential diagnosis of patients presenting with suspicious soft tissue masses. Future studies may help to elucidate the natural history of this disease process, as well as the possibility for malignant potential, thus permitting the development of more evidence-based treatment strategies. Until then, known RDD lesions should be excised using established surgical principles. 


\section{Consent}

Written informed consent was obtained from the patient for publication of this case report and any accompanying images. A copy of the written consent is available for review by the Editor-in-Chief of this journal.

\section{Abbreviations}

H \& E: Hematoxylin and eosin; IFN: Interferon; LCH: Langerhans cell histiocytosis; RDD: Rosai-Dorfman disease; SHML: Sinus histiocytosis with massive lymphadenopathy.

\section{Competing interests}

The authors declare that they have no competing interests.

\section{Authors' contributions}

MK and LSS reviewed the literature and drafted the manuscript. RSC was clinically responsible for the patient's care and revision of the manuscript $M D$ and MLS were responsible for the pathology. All authors read and approved the final manuscript.

\section{Author details}

'Saint George's University School of Medicine, University Centre, Grenada, West Indies. ${ }^{2}$ Department of Surgery, Saint Barnabas Medical Center, 94 Old Short Hills Road, Livingston, NJ 07039, USA. ${ }^{3}$ Department of Pathology, Saint Barnabas Medical Center, 94 Old Short Hills Road, Livingston, NJ 07039, USA ${ }^{4}$ Department of Surgery, University of Medicine and Dentistry of New Jersey 185 South Orange Avenue, Newark, NJ 07013, USA.

Received: 21 July 2012 Accepted: 16 February 2013

Published: 9 March 2013

\section{References}

1. Kong Y, Kong J, Shi D, Lu H, Zhu X, Wang J, Chen Z: Cutaneous RosaiDorfman Disease: a clinical and histopathologic study of 25 cases in China. Am J Surg Pathol 2007, 21:341-350.

2. Potts C, Bozeman A, Walker A, Floyd W: Cutaneous Rosai-Dorfman disease of the forearm: case report. J Hand Surg Am 2008, 33A:1409-1413.

3. Penna Costa AL, Oliveira e Silva N, Motta MP, Athanazio RA, Athanazio DA, Athanazio PRF: Soft tissue Rosai-Dorfman disease of the posterior mediastinum. J Bras Pneumol 2009, 35:717-720.

4. Tan HY, Kao LY: Rosai-Dorfman disease manifesting as relapsing uveitis and subconjunctival masses. Chang Gung Med J 2002, 25:621-625.

5. Yoon A, Parisien M, Feldman F, Young-In Lee F: Extranodal Rosai-Dorfman disease of bone, subcutaneous tissue and paranasal sinus mucosa with a review of its pathogenesis. Skeletal Radiol 2005, 34:653-657.

6. Montgomery EA, Meis JM: Rosai-Dorfman disease of soft tissue. Am J Surg Pathol 1992, 16:122-129.

7. Suster S, Cartagena N, Cabello-Inchausti B, Robinson MJ: Histiocytic lymphphagocytic panniculitis: an unusual extranodal presentation of sinus histiocytosis with massive lymphadenopathy (Rosai-Dorfman disease). Arch Dermatol 1988, 124:1246-1249.

8. Rasool MN, Ramdial PK: Osseous localization of Rosai-Dorfman disease. $J$ Hand Surg Br 1996, 21B:349-350

9. Govender D, Chetty R: Inflammatory pseudotumour and Rosai-Dorfman disease of soft tissue: a histological continuum? J Clin Pathol 1997, 50:79-81.

10. Child FJ, Fuller LC, Salisbury J, Higgins EM: Cutaneous Rosai-Dorfman disease. Clin Exp Dermatol 1998, 23:40-42.

11. Quaglino P, Tomasini C, Novelli M, Colonna S, Bernengo MG: Immunohistologic findings and adhesion molecule pattern in primary pure cutaneous Rosai-Dorfman disease with xanthomatous features. Am J Dermatopathol 1998, 20:393-398.

12. Huang H, Liang C, Yang B, Sung M, Lin J, Chen W: Isolated Rosai-Dorfman disease presenting as peripheral mononeuropathy and clinically mimicking a neurogenic tumor: case report. Surg Neurol 2001, 56:344-347.

13. Stefanato CM, Ellerin PS, Bhawan J: Cutaneous sinus histiocytosis (RosaiDorfman disease) presenting clinically as vasculitis. J Am Acad Dermatol 2002, 46:775-778.
14. Molina-Garrido MJ, Guillen-Ponce C: Extranodal Rosai-Dorfman disease with cutaneous periodontal involvement: a rare presentation. Case Rep Oncol 2011, 4:96-100.

15. Shi X, Ma D, Fang K: Cutaneous Rosai-Dorfman disease presenting as a granulomatous rosacea-like rash. Chin Med J (Engl) 2011, 124:793-794.

16. Sodhi KS, Suri S, Nijhawan R, Kang M, Gautam V: Rosai-Dorfman disease: unusual cause of diffuse and massive retroperitoneal lymphadenopathy. Br J Radiol 2005, 25:845-847.

17. Ensari S, Selcuk A, Dere H, Perez N, Dizbay Sak S: Rosai-Dorfman disease presenting as laryngeal masses. Kulak Burun Bogaz Ihtis Derg 2008, 18:110-114

18. Pinto DCG, Vidigal TA, Castro B, Santos BH, DeSousa NJA: Rosai-Dorfman disease in the differential diagnosis of cervical lymphadenopathy. Bras $J$ Otorrinolaringol 2008, 74:632-635

19. Levine $\mathrm{PH}$, Jahan $N$, Murari $\mathrm{P}$, Manak M, Jaffe ES: Detection of human herpesvirus 6 in tissues involved by sinus histiocytosis with massive lymphadenopathy (Rosai-Dorfman disease). J Infect Dis 1992, 166:291-295.

20. Luppi M, Barozzi P, Garber R, Maiorana A, Bonacorsi G, Artusi T, Trovato R, Marasca $R$, Torelli G: Expression of human herpesvirus- 6 antigens in benign and malignant lymphoproliferative diseases. Am J Pathol 1998, 163:815-823.

21. Stebbing C, van der Walt J, Ramadan G, Inusa B: Rosai-Dorfman disease: previously unreported association with Sickle cell disease. BMC Clin Path 2007, 7:3.

22. Moore J, Zhao X Nelson E: Concomitant sinus histiocytosis with massive lymphadenopathy (Rosai-Dorfman disease) and diffuse large B-cell lymphoma: a case report. J Med Case Reports 2008, 2:70.

23. Woodcock R, Madell J, Lipper M: Sinus histiocytosis (Rosai-Dorfman disease) of the suprasellar region: MR imaging findings - a case report. Radiology 1999, 213:808-810.

24. Lu D, Estalilla OC, Manning JT, Medeiros J: Sinus histiocytosis with massive lymphadenopathy and malignant lymphoma involving the same lymph node: a report of four cases and review of the literature. Mod Pathol 2000, 13:414-419.

25. Shea CR, Elston DM: Langerhans Cell Histiocytosis. http://emedicine. medscape.com/article/1100579-overview.

26. Kemson R, Rouse R: Inflammatory Myofibroblastic Tumor. Surgical pathology criteria. Stanford, CA: Stanford School of Medicine; 2008. http:// surgpathcriteria.stanford.edu/softfib/inflammatory_myofibroblastic_tumor/.

27. Sabel MS: From sarcomas of bone and soft tissue. In Greenfield's Surgery: Scientific Principles and Practice. 5th edition. Edited by Greenfield LJ, Mulholland MW, et al. Philadelphia, PA: Wolters Kluwer Health/Lippincott William and Wilkins: 2011:2151-2176.

28. Konishi E, Ibayashi N, Yamamoto S, Scheithauer BW: Isolated intracranial Rosai-Dorfman disease (sinus histiocytosis with massive lymadenopathy). Am J Neuroradiol 2003, 24:515-518.

29. Podberezin M, Angeles R, Guzman G, Peace D, Gaitonde S: Primary pancreatic sinus histiocytosis with massive lymphadenopathy (RosaiDorfman disease): an unusual extranodal manifestation clinically simulating malignancy. Arch Pathol Lab Med 2010, 134:276-278.

doi:10.1186/1477-7819-11-63

Cite this article as: Komaragiri et al:: Extranodal Rosai-Dorfman disease: a rare soft tissue neoplasm masquerading as a sarcoma. World Journal of Surgical Oncology 2013 11:63. 